\title{
Balloon Vaginoplasty: A Revolutionary Approach for Treating Vaginal Aplasia
}

\author{
Atef M.M. Darwish \\ Woman's Health University Center, Assiut, \\ Egypt
}

\section{Introduction}

Vaginal aplasia is a rare anomaly that carries psychologic, physical and sexual problems to the female and her partner. Whereas a number of vaginoplasty methods have been developed, refined, and modified, no state-of-the-art surgical approach has been established. This is due to a number of factors including regional differences, surgeon experience and preference for a method, and patient choice. The goal of vaginoplasty is to develop a space between the bladder and the rectum suitable for satisfactory intercourse for both partners.

This review will discuss in details the common available procedures of vaginoplasty with stress on the evident pros and cons of each technique. Thereafter, it will discuss the new era of balloon vaginoplasty whether done laparoscopically or via the retropubic space. Every procedure will be discussed meticulously with excellent illustrations. Some tables to compare different techniques will be provided. In short, a step by step educational approach will be delivered to the readers to start practicing such simplified procedures in their own hospitals.

\section{Background}

Vaginal aplasia (figures 1-3) is a rare anomaly occurring in approximately 15,000 to 10,000 births (1). It carries an emotional, sexual, and social embarrassing effect on those women $(2,3)$. Previously, those cases are neglected by the general gynecologists and sent to be treated by very limited specialized centers all over the word. Thanks to continuous refinement and innovation of reconstructive surgical techniques, some of those women could be able to conceive (4-6). Even if this anomaly is associated with uterine aplasia, there is a hope for uterine transplantation within the coming few years $(7,8)$ because of successful animal transplantation $(9,10)$ and competent organ cryopreservation (11). These modern achievements pushed interested centers to refine their procedures and offer those cases the best available care.

Mayer-Rokitansky-Kuster-Hauser syndrome (MRKHS) is a subtype of vaginal agenesis comprising congenital absence of vagina and a variety of Mullerian duct anomalies, with aplasia of the uterus being the most common feature. In general, these patients have normally functioning ovaries, which are often located at the pelvic brim (figure 3). Anomalies of the urinary tract and the skeleton are frequently associated with MRKHS (12). 


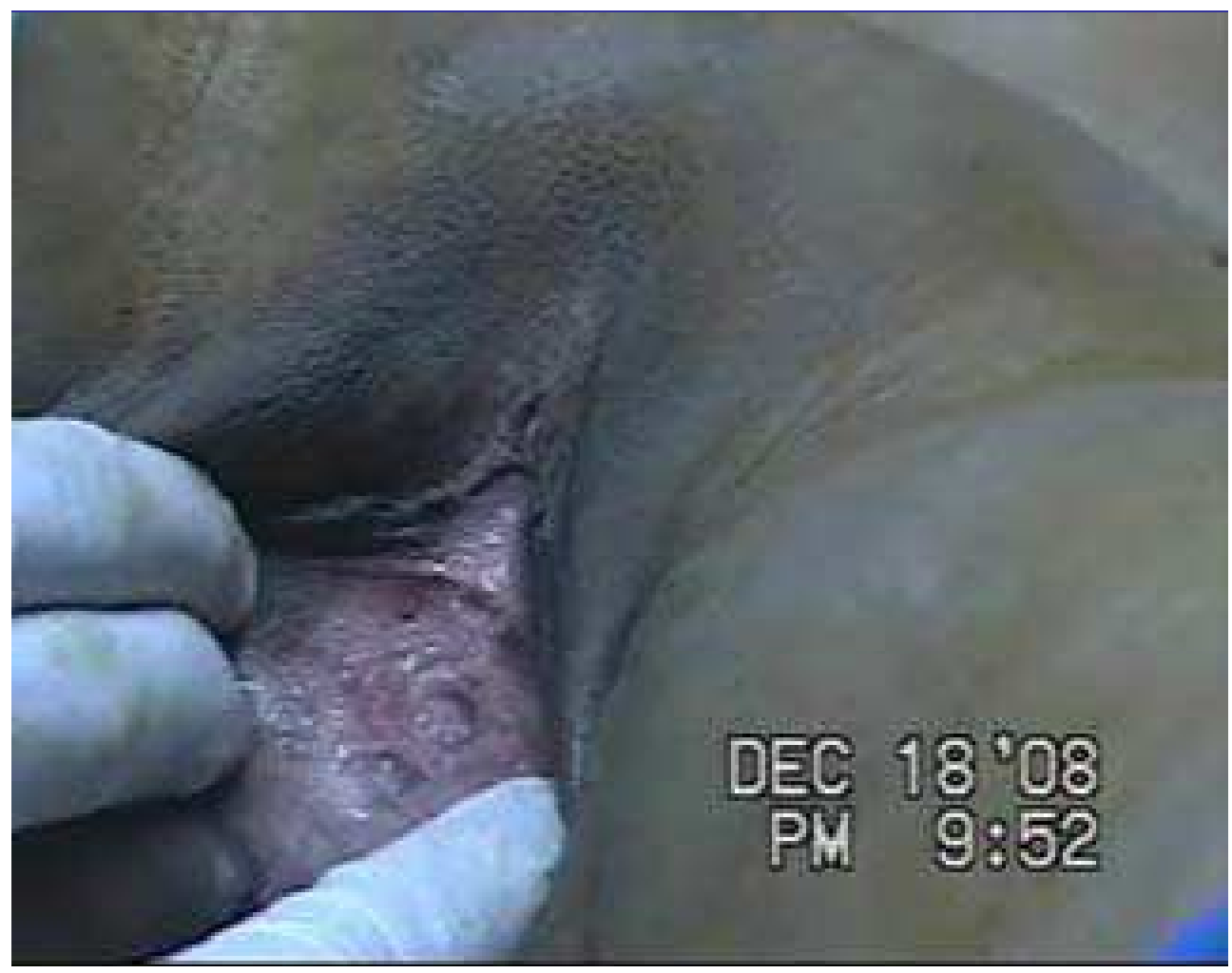

Fig. 1. Clinical appearance of vaginal aplasia.

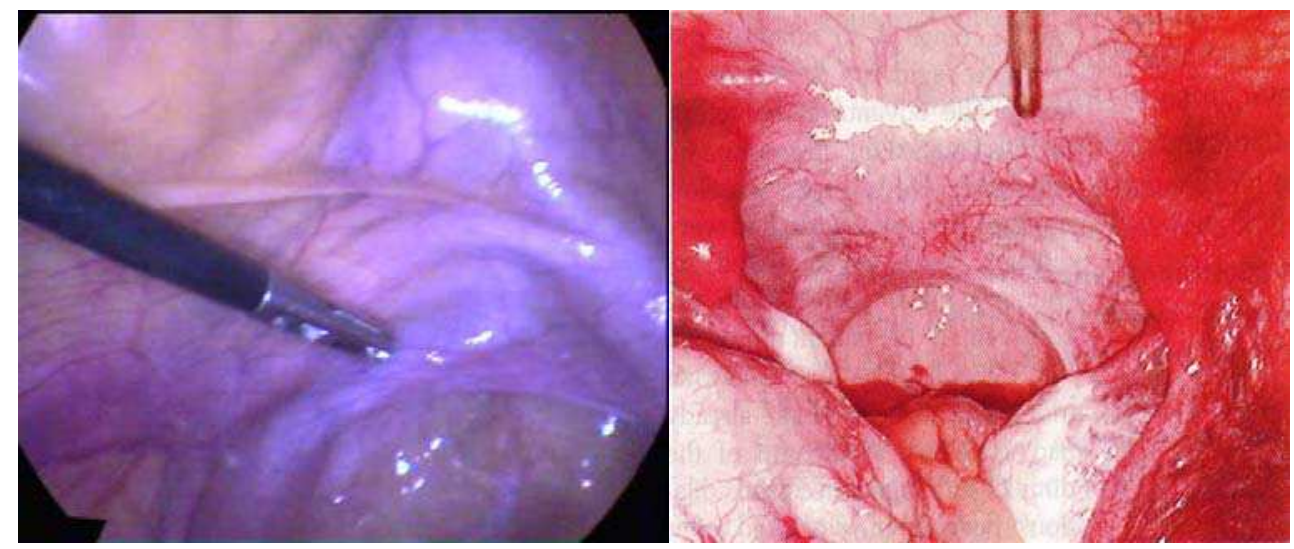

Fig. 2. Laparoscopic appearance of vaginal aplasia 


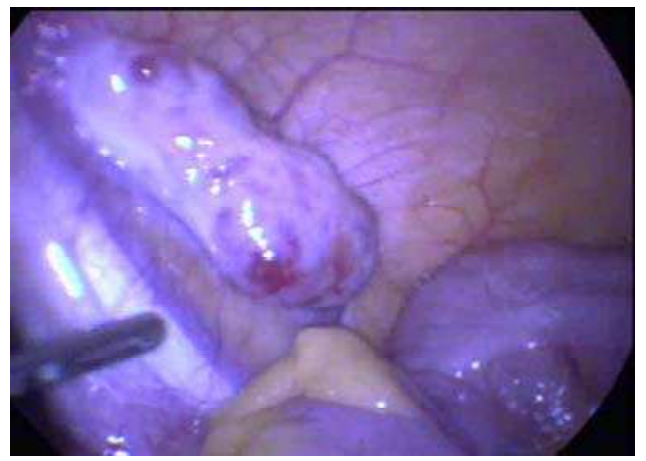

Fig. 3. Abnormal localization of the ovaries in MRKH syndrome.

\section{Therapeutic options of vaginoplasty}

Numerous surgical and nonsurgical procedures with varying degrees of success have been described for correction of the condition, but none have proved to be universally accepted. As this chapter is planned to focus on balloon vaginoplasty, I just quote some references on the common techniques of vaginoplasty (13-29). A lot of the published work on vaginoplasty demonstrates the feasibility of a particular procedure, highlights its possible advantages, and expresses the skills of the surgeons. The question now is not whether the procedure is feasible, but whether the approach is superior and beneficial to a particular patient, cost effective for the community at large, and more importantly easily performed by the general gynecologists without sophisticated instrumentation. The following algorism (figure 4) summarizes broadly the different methods of vaginoplasty.

\section{Different therapeutic options}

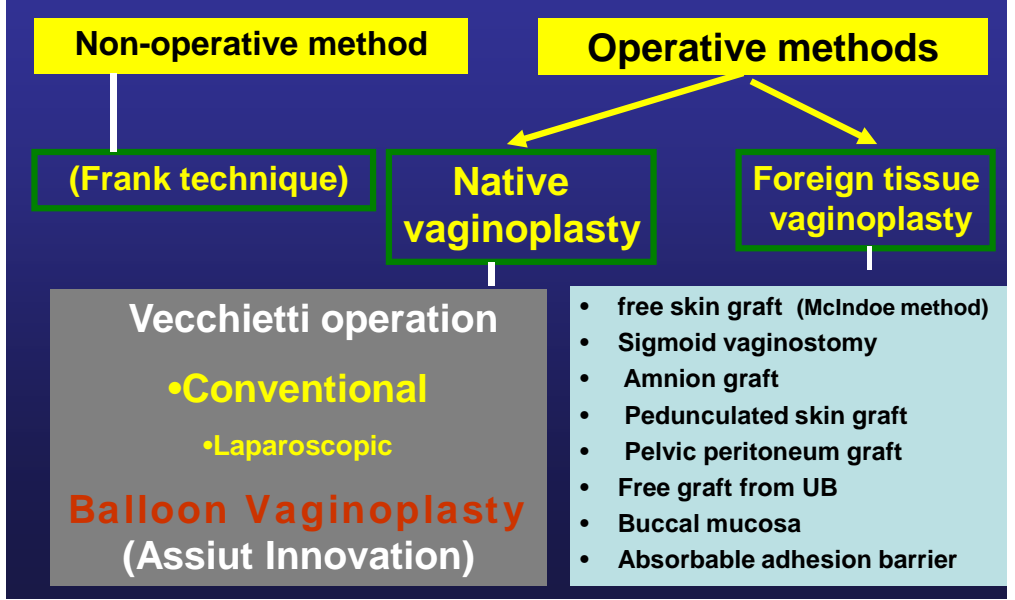

Fig. 4. Classification of vaginoplasty techniques. 


\subsection{Conventional surgery}

Gynecologic surgeons or gynecologic endoscopists of average experience would find most of the published surgical techniques of vaginoplasty sophisticated and difficult to perform, and both cost and effectiveness must be considered conjointly when evaluating new surgical procedures. Given the rarity of the condition and the number of available methods, outcome data can be difficult to obtain (30). The traditional operative techniques (31) have major disadvantages, including prolonged recovery time and significant scarring (32). These techniques require lengthy, often embarrassing self-catheterization, which can be painful, and they may yield a vagina of only limited length (33). Many centers prefer Vecchietti's neovaginoplasty because of its low perioperative morbidity and quicker recovery period (34). These conventional surgical procedures are tedious, time consuming, and require a higher level of surgical expertise.

\subsection{Laparoscopic approach}

As described by Cooper et al. (35), laparoscopic neovagina can be created by drawing an olive into the vaginal grove and applying continuous tension via sutures passed at laparoscopy to a tensioning device on the anterior abdominal wall (35) using different instrument sets (36).
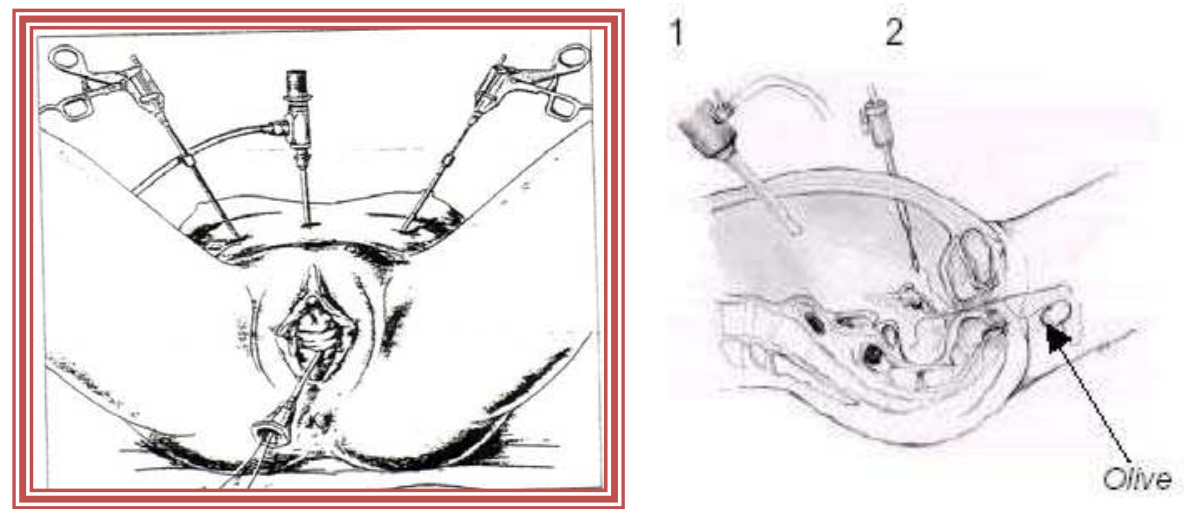

Fig. 5. Laparoscopic Vecchietti procedure

However, there are risks inherent in the most difficult step, passing the thread-bearing cutting needle from the abdominal wall to the retrohymenal fossa, through the vesicorectal space (37). It is important to ensure bladder and rectal integrity (38). Ultrasonographic control may increase safety (39).

\subsection{Disadvantages of the Vecchietti procedure:}

It requires specialized teams utilizing sophisticated instrumentation, however, and it is tedious to perform. It has the drawbacks of requiring daily traction for 8 to 10 days. Moreover, it lifts the posterior urethrovesical angle, making it more obtuse, with the possible consequence of causing stress incontinence later on (the posterior traction on the urethral supports also placing the patient at higher risk for stress incontinence). Furthermore, a change in the pelvic floor balance has been suspected (40). Another problem with the Vecchietti vaginoplasty is the use of a special abdominal traction device for a few days (41). 
Other laparoscopic procedures are more complicated and tedious, such as the Davydov procedure (32) or sigmoid colpoplasty $(42,43)$. Soong (44) described a laparoscopically assisted neovaginoplasty in which laparoscopic dissection of the rectovesical space is followed by traction of the pelvic peritoneum by a vaginal clamp and insertion of a vaginal stent for 1 week (45). The latter is not a pure laparoscopic approach and appears to be time consuming, although Soong did not comment on the operative time.

\subsection{Advantages of laparoscopic approach}

Apart from the common well established advantages of laparoscopic surgery over the conventional surgery, laparoscopy permits identification of the pelvic peritoneum as well as the proper site for the summit of the neovagina using the most mobile portion to form the vaginal fornix. Laparoscopy significantly facilitates this procedure, reduces operating time and risks, and makes the operation available to a wide range of surgeons skilled in laparoscopy (46).

\subsection{Missing data in the previous studies:}

The question is not whether the procedure is feasible, but whether the approach is superior and beneficial to a particular patient, cost effective for the community at large, and more importantly easily performed by the general gynecologists without sophisticated instrumentation. These guidelines constructed the frame of our institutional research on neovaginoplasty in recent years.

\begin{tabular}{|c|c|c|}
\hline $\begin{array}{l}\text { Examples and } \\
\text { characteristics }\end{array}$ & Vaginoplasties with grafts & Vaginoplasties without grafts \\
\hline & $\begin{array}{c}\text { Free skin graft (the McIndoe } \\
\text { method) } \\
\text { - Sigmoid vaginostomy } \\
\text { - Amnion graft } \\
\text { - Pedunculated skin graft } \\
\text { - Pelvic peritoneum graft } \\
\text { - Free UB graft } \\
\text { - Grafts from the buccal } \\
\text { mucosa }\end{array}$ & $\begin{array}{c}\text { The Vecchietti operation [7], which can be } \\
\text { Conventional } \\
\text { Laparoscopic balloon vaginoplasty } \\
\text { Nonanatomic access to the vaginal dimple } \\
\text { The posterior urethrovesical angle is lifted, } \\
\text { which makes it more obtuse } \\
\text { A change in the balance of the pelvic floor has } \\
\text { been suggested }\end{array}$ \\
\hline
\end{tabular}

Table 1.

\section{Balloon vaginoplasty innovation}

This concept is developed at Assiut University (Egypt) by our team in 2007. Its main goal is to introduce a simplified approach that can be done by many gynecologists all over the world. As any innovation, it quickly passed through sequential steps of modifications to get the best available safe as well as effective approach.

\subsection{Advantages of native balloon vaginoplasty over foreign tissue vaginoplasty}

Cancer of the neovagina created by exogenous tissue, for example, bowel, skin graft, vulvar skin flaps, rectus abdominis (myocutaneous) flaps, or inverted penile skin, has been documented at younger ages than cancer of the native vagina (47). Tissue dysplasia can be 
expected because the tissue is suddenly subjected to new contacts or stresses (47). Therefore, recent interest has focused on dilatation as a treatment of choice $(48,49)$. Most of the international centers promote the use of vaginal dilators (50). The success rate is reported to be up to $81 \%$ after vaginal dilatation (51). This can be attributed to the inherent nature of the vagina in the form of a high capability of elasticity and dispensability. Vaginal maximal tissue elongation is proved to be higher than that of normal skin (49). It seems logical that dilatation or other surgical procedures based on proper understanding of the nature of this organ would be preferred over techniques based on the idea of replacement of the vagina by skin, amniotic membrane, sigmoid, or otherwise. Moreover, replacement techniques would lead to scar formation. The prevalence of dyspareunia increases after transvaginal reconstructive pelvic surgeries (52). This concept stands behind the increased popularity of the conventional or laparoscopic Vecchietti operation as it is devoid of vaginal scars. Of peculiar advantages of balloon vaginoplasty particularly retropubic balloon vaginoplasty is the possibility of surgical intervention for recurrent or failed cases done by other procedures. Herein, I'll summarize the different techniques of balloon vaginoplasty.

\section{Laparoscopic balloon vaginoplasty after dissection of the rectovesical pouch (53):}

Under general endotracheal anesthesia, a standard laparoscopy evaluation is performed with two auxiliary 5-mm suprapubic portals. Dissection of the peritoneum covering the vesicorectal pouch is performed. A piece of gauze is inserted inside the rectum and is gently manipulated by a nurse in different directions, as directed by the surgeon. A metal catheter is inserted into the bladder, which is moved according to the directions of the surgeon. Gentle, sharp dissection of the vesicorectal space is done until a free area in between is achieved. Dissection then should be progressed until near the vaginal skin. The left 5-mm suprapubic trocar is extracted, followed by advancement of a blunt-ended grasper to make a gentle dissection of the peritoneum until reaching the dissected area. A 18F silicone Foley catheter is advanced extraperitoneally to replace the left-side blunt-ended grasper up to the dissected area. From the right side, blunt-ended grasping forceps are pushed into the rectovesical space. Vaginally, a snip is made on top of it, followed by advancement of another grasper to pick up the tip of the catheter vaginally. The balloon is inflated with 6 cm3 saline while the catheter is advanced upward; tension is maintained by applying two disposable umbilical cord clamps on the stretched catheter. To avoid skin ischemia or pain at the site of traction, a sterile dressing is insinuated beneath the clamps. To be fitted, a small hole is made at the center of the dressing before its application below the clamps. Maximal tension is achieved by continuous traction before applying the clamps (Fig. 6). The integrity

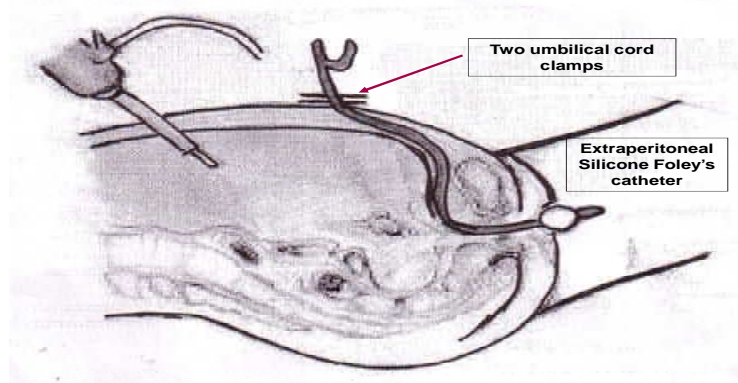

Fig. 6. Lateral view of the extrapeeritoneal catheter 
of the bladder is easily checked by gentle testing using the blunt tip of a metal catheter. All laparoscopic instruments are extracted without any suturing. A Foley catheter is inserted into the urethra.

\section{Disadvantages:}

Despite being extraperitoneal, nevertheless, this procedure requires a considerable experience of laparoscopic surgery to dissect rectum from the bladder safely.

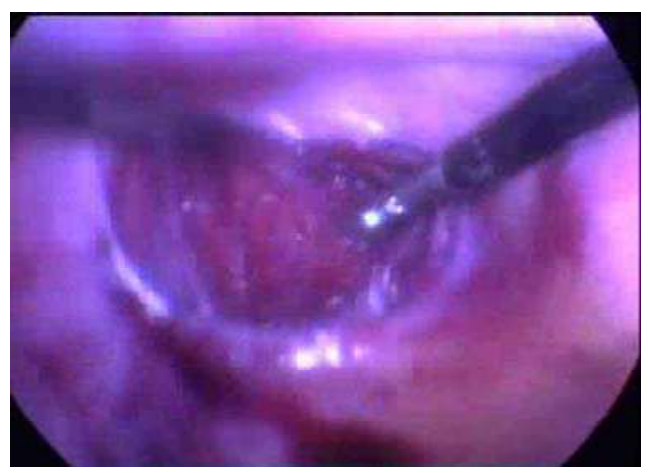

Fig. 7. Dissection of rectovesical space.

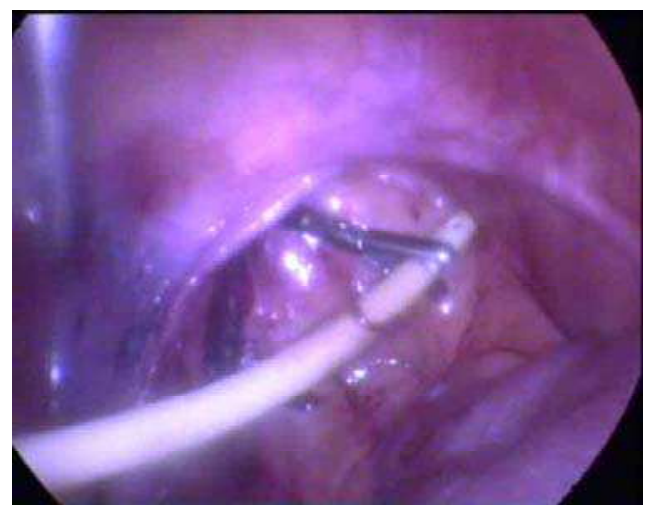

Fig. 8. Extraction of the catheter via the vaginal dimple.

2. Laparoscopic balloon vaginoplasty without dissection of the rectovesical pouch $(54,55)$

A silicon coated balloon catheter is manipulated by a specially designed inserter, which is passed transperitoneally and through the pelvic floor where the balloon is positioned at the vaginal dimple. An upward, gradual $(1-2 \mathrm{~cm} /$ day) traction is applied on the catheter stem from the abdominal side for one week. A concomitant increase in balloon capacity $(5 \mathrm{ml}$ 
every other day) to increase the width of the neovagina is also done. Sexual relations are recommended as early as one week after surgery.

\section{Disadvantages:}

Despite being an easy procedure, it is a blind and intraperitoneal approach. Practically, an extraperitoneal approach is proved to be effective and carries no risk of coiling of some loops of intestine or peritoneal irritation.

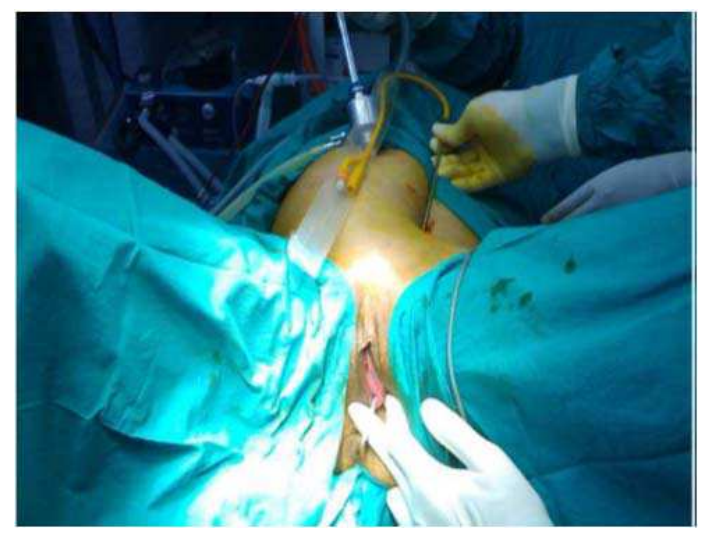

Fig. 9. Insertion of a specialty designed inserter.
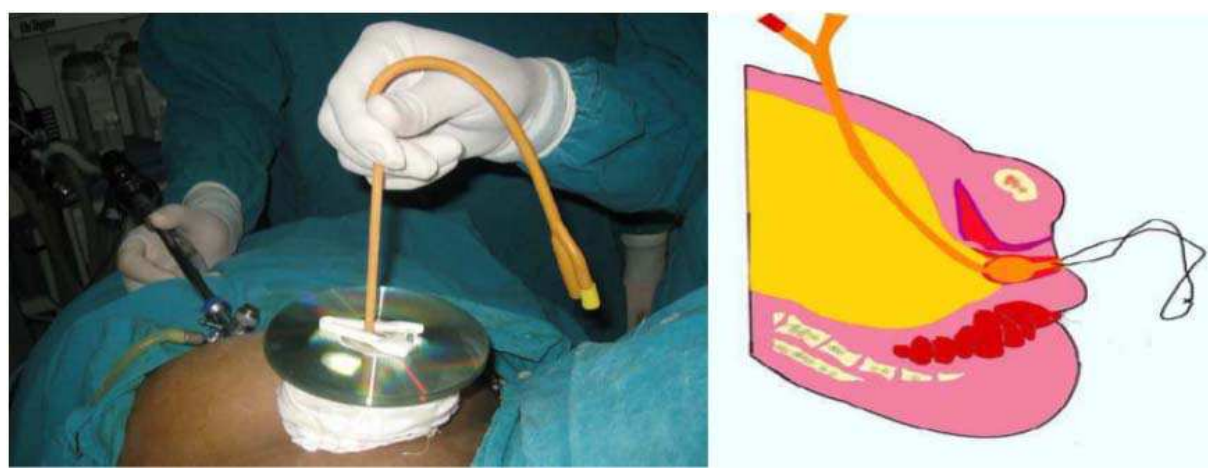

Fig. 10. Postoperative view.

\section{Modified laparoscopically assisted BV $(56,57)$ :}

The procedure starts with diagnostic laparoscopy (video). After full evaluation of intraabdominal and intrapelvic structures, the telescope is directed toward the pelvic floor. A suction irrigation cannula is introduced through the ancillary abdominal puncture and pushed firmly against the pelvic floor in the region of the pouch of Douglas (Figure 11). Simultaneously, using palpation, the tip of the cannula is introduced transperineally through the vaginal dimple, positioning it so that it presses at a central point of the dimple. The surgeon's right hand held the cannula from the abdominal side, and the left hand guides the pressed tip of the cannula from the perineal side. Next, a conventional surgical 
needle, its curve attenuated, is threaded with a long, double-stranded silk suture (DSSS) and passed through the vaginal dimple at the point where the cannula tip is positioned. The needle perforates the pelvic floor, and as it appears at the pouch of Douglas, the cannula is removed and a laparoscopic grasper/needle-holder is inserted so that the needle could be extracted through the ancillary abdominal puncture (Figure 12). Then, the needle is removed from the DSSS, and the suture is threaded into the opening of an 18-gauge silicon coated Foley's catheter. Traction is exerted on the DSSS from the perineal side until the catheter is pulled back through the abdominal port to the pelvic floor and through the pelvic floor to the dimple (Figure 13). This step is greatly facilitated by exerting counter traction on the catheter, stretching it to decrease its caliber especially while it is moved through the pelvic floor, since the channel created by the needle is very narrow. After the balloonbearing end of the catheter appears at the dimple, it is inflated with $15 \mathrm{~mL}$ of saline. Traction is exerted from the abdominal side until the balloon moved up, carrying the stretched dimple above the introitus. Catheter placement in past procedures relied on a unique catheter inserter, but the catheter can be manipulated into position using a suction irrigation cannula and a surgical needle. Traction on the catheter is maintained without the supporting plate that had been expressly made for that purpose. Traction on the catheter should be maintained using a supportive plate. It may be made of stainless steel and sterilized by autoclave, closely resembles a DVD disk. In the first method, a thick, multilayered dressing is tightly wrapped around the catheter, until a cylinder, at least $5 \mathrm{~cm}$ high and $10 \mathrm{~cm}$ wide, is formed perpendicular to the abdomen. The outermost layer of the dressing is encircled with

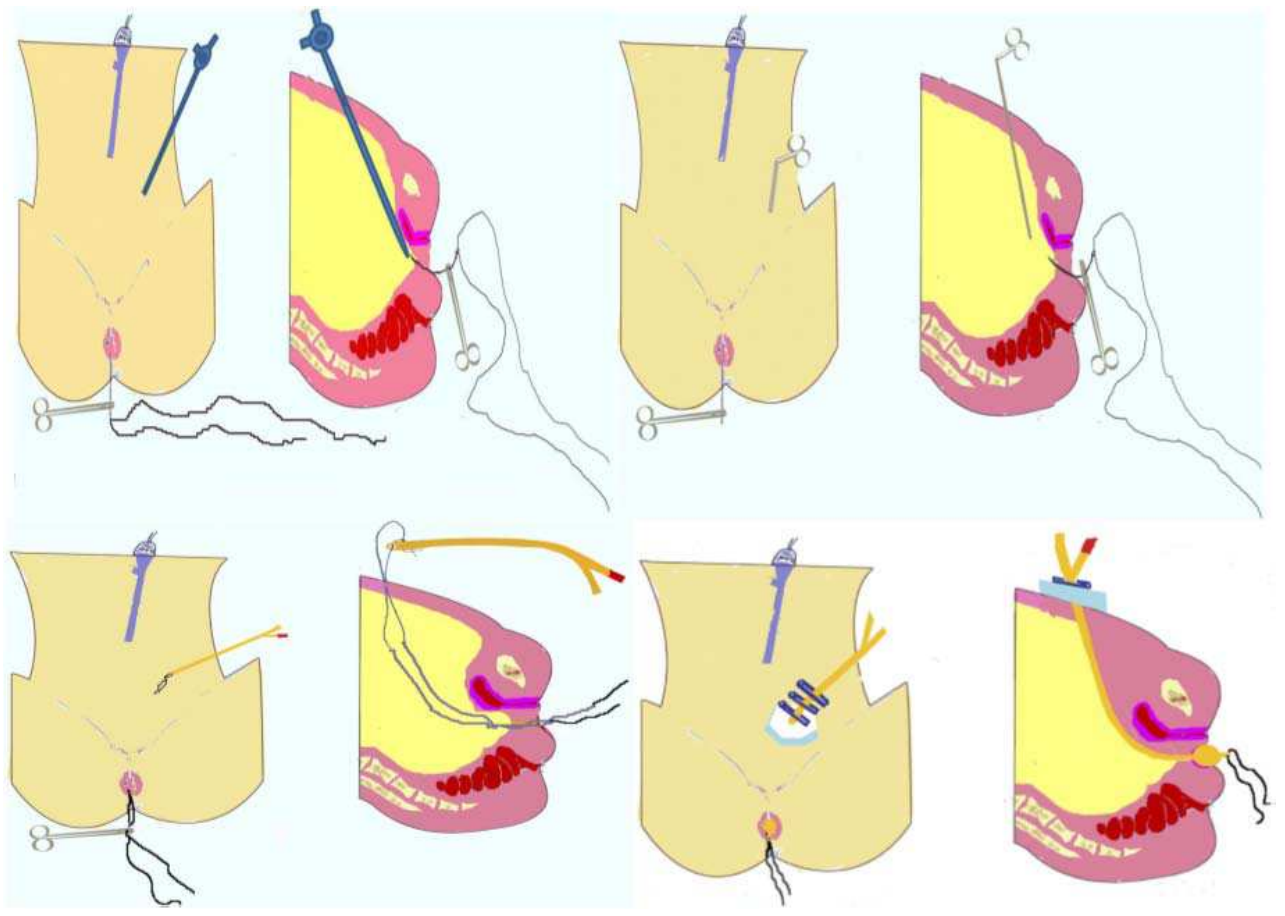

Fig. 11.-14. Modified laparoscopic intraperitoneal balloon vaginoplasty. 
adhesive tape to guard against unraveling (Figure 14). In addition, the cord clamp would be well supported away from the abdominal wall, thus preventing pressure necrosis. An alternative supporting plate made of 3 DVDs joined together with silicon and sterilized with ethylene oxide can be used. It is placed around the catheter and over a dressing so that it distributed the force from traction over a wide surface area, preventing pressure sloughing of the abdominal skin. Postoperative care is the same as that previously described for BV and included controlled traction and distension, prevention of infection, continued psychosocial support, and emphasis on early resumption of sexual activity; patients are instructed to use a condom and gentamicin cream during the first 10 days after discharge.

\section{Disadvantages:}

It seems to be non applicable by the general gynecologists as it is an intraperitoneal approach with a risk of subsequent intestinal coiling, risky as they reported a case of rectal injury out of three cases (33.3\%) added to the risks of laparoscopy particularly if the patient has a scar of correctiob of other malformations or pelvic surgery.

\section{Space of Retzius (figure 15)}

In 1858, Retzius described the eponymous space, situated anterior and lateral to the urinary bladder (prevesical space) (58). It is the space between the symphysis, the bladder, and the anterior abdominal wall. It is bordered anteriorly by the pelvic bone; posteriorly by the endopelvic fascia (the urogenital, pubocervical, and pelvic fascia, which cover the bladder and the urethra); and laterally by the obturator muscle. It contains loose connective tissue and fat and affords the surgeon access to the bladder without opening the peritoneal cavity. It is an optimal extraperitoneal approach well addressed in the field of urogynecology. Access though it would eliminate laparoscopy and its complications. Moreover, because of its proximity, it seems logical to access the vaginal dimple through it rather than through the auxiliary laparoscopic portals.

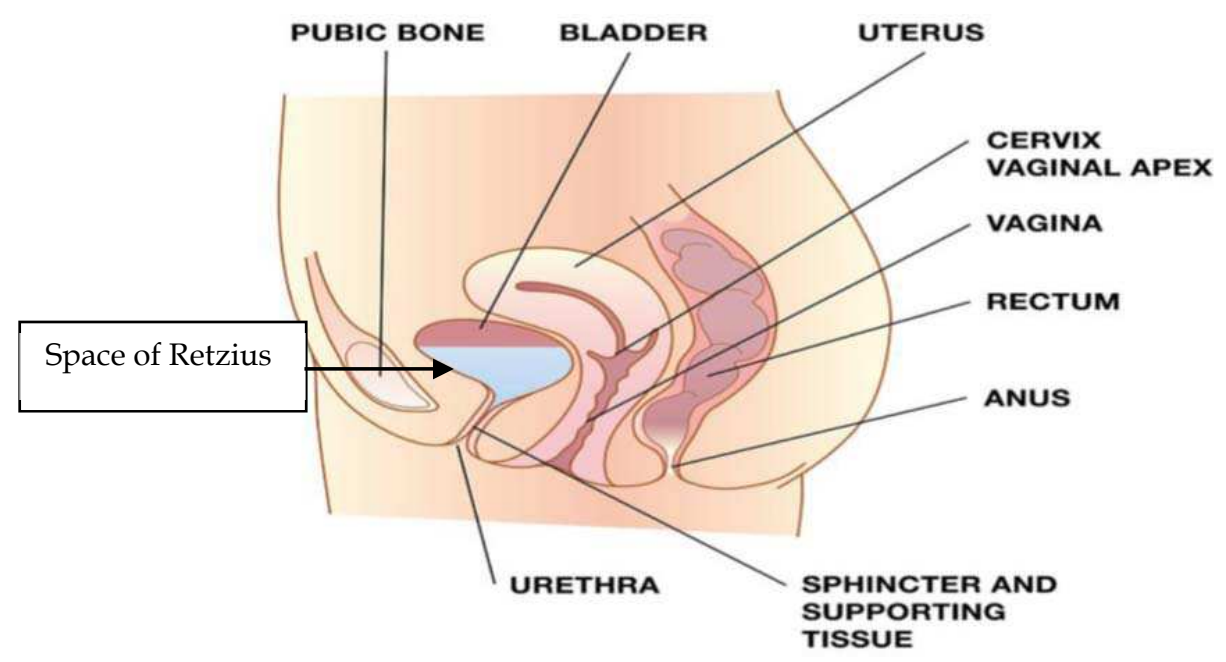

Fig. 15. 


\section{Retropubic fine needle vaginoplasty (59)}

Patients are prepared as usual for any simple gynecologic operation. Under IV propophol anesthesia, the bladder is evacuated followed by insertion of a rigid catheter guide (bladder stylet) loaded inside a urethral catheter. It aims to mobilize the bladder neck away from the tip of the needle when it passes into the retropubic space. A $7 \mathrm{~mm}$ suprapubic incision is made just lateral to the midline in the suprapubic area $2 \mathrm{~cm}$ above the symphysis pubis in the same manner as tension free traction (TVT) operation for treating genuine stress incontinence (60). A fine single lumen egg retrieval needle with its stainless handle tightly fitted to a cut distal end of a Foley catheter is used. We prefer Swemed Sense needle (Virtolife Sweden AB, Kungsbacka, Sweden) which has a reduced distal end of $0.9 \mathrm{~mm}$ OD while the rest of the needle has $1.4 \mathrm{~mm}$ OD (Figure 16). An additional advantage of this needle is good malleability that allows bending of the needle during insertion to adapt the curve of space of Retzius (Figure15). The bended needle is inserted through the suprapubic incision directed towards the space of Retzus with simultaneous mobilization of the bladder inwards and laterally into the ipsilateral side with the bladder stylet. To help the needle reach the correct place in the center of the vaginal dimple, a small incision in the vaginal dimple is made which is used to allow the introduction of the operator's contraletral index finger to guide the tip of the fine needle. Once the tip of the needle appears, the bladder catheter is removed followed by cystoscopic examination. If the bladder is intact, the needle is advanced with some force to allow the fitted catheter to bypass the anterior abdominal wall layers. Once the balloon is seen from the vaginal side, it is disconnected from the needle, inflated with 6-8 cc of saline, and pulled upwards (figure 16). Traction is maintained by applying two alternating umbilical cord plastic clamps on its part adjacent to the anterior abdominal wall. To avoid skin ischemia, an intervening layer of sterile gauze is placed underneath a stainless steel fenestrated plate (Figure 17). To avoid retention effect of the balloon, a urethral catheter is inserted and fixed. After a short postoperative interval, before discharge, the patient is instructed to maintain antibiotic coverage and to take a nonsteroidal anti-inflammatory drug whenever required. She is taught how to evacuate and care for the urine collection bag, make frequent proper vaginal douches using bovidone iodine $10 \%$, and apply sterile vulvar dressings to guard against ascending infection. Three days later, she has to come to the office for more traction on the catheter which is maintained using a third umbilical clamp. The abdominal and the uretheral catheters are removed on day 8 .

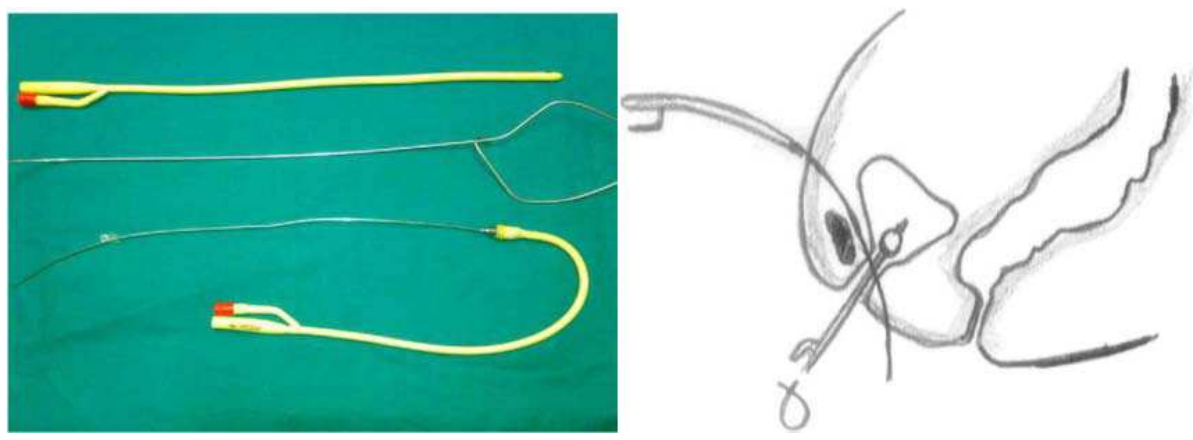

Fig. 16. Instrumentation and a diagram of fine needle vaginoplasty 


\section{Disadvantages:}

Despite being simple, it is a relatively unsafe as the needle is passed blindly towards the vaginal dimple sometimes after several trials. There is a risk of needle puncture of the surgeon's fingers. Moreover, the needle is malleable and unstable during its perforation of the retropubic space. Lastly, the vaginoabdominal approach is more comfortable than abdominovaginal approach used during the fine needle procedure.

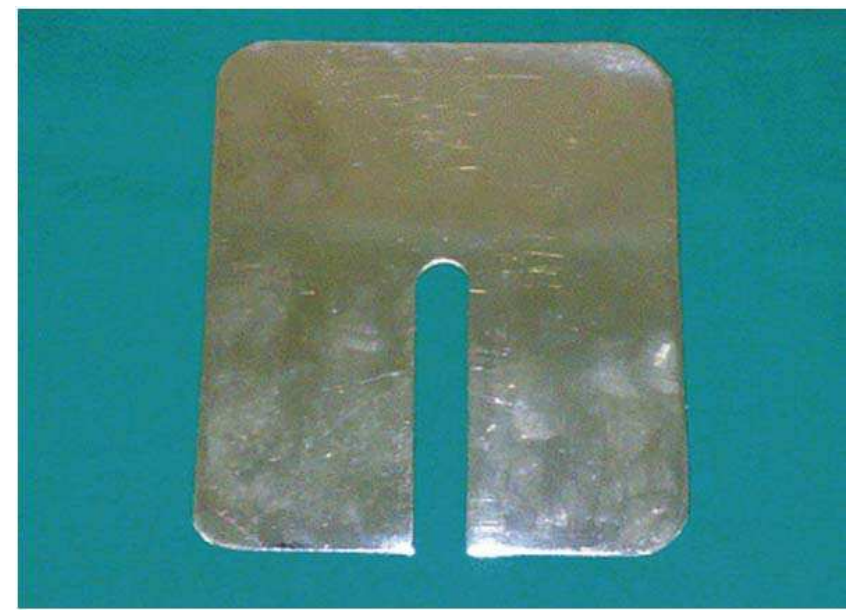

Fig. 17. Stainless steel fenestrated plate

\section{Transretropubic traction vaginoplasty (TRT) (60)}

Using an olive rather than balloon but goes along the road of balloon vaginoplasty that's why I preferred to include it here.

Idea: In the course of a few days, a plastic olive placed on the vaginal dimple is lifted by a mesh tape inserted through the space of Retzius and anchored to the anterior abdominal wall. The upward traction exerted on the vaginal dimple is sufficient to create a neovagina.

\section{Steps}

The patients are prepared for the TRT vaginoplasty as for any simple gynecologic surgical procedure. Under general anesthesia, bladder evacuation is followed by the insertion of a urethral catheter, through which a rigid guide (or bladder stylet) is then passed. This step is taken to mobilize the bladder neck away from the tip of the needle when it passed into the retropubic space. A 7-mm incision is then made on both sides in the suprapubic area, $2 \mathrm{~cm}$ from the midline and $2 \mathrm{~cm}$ above the symphysis pubis, as if to install tension-free vaginal tape to treat stress urinary incontinence (61). A sharp, curved needle especially designed with a wide eye attached to a plastic handle (Fig. 18) is used to perforate the vaginal dimple bilaterally, just $1 \mathrm{~cm}$ below the bladder neck. A strip of mesh composed of a knitted polypropylene monofilament (Pro Mesh (Ethicon, Somerville, NJ, USA), $1 \mathrm{~cm}$ in width and $30 \mathrm{~cm}$ in length, is stretched and passed through the eye of the needle. A $2 \times 3 \mathrm{~cm}$, fenestrated plastic olive is threaded like a bead on the tape. The needle is inserted through the vaginal dimple skin without prior incision, directed upwards and slightly laterally 
toward the space of Retzius, with simultaneous mobilization of the bladder inwards and laterally on the same side with the bladder stylet. After which, the needle is directed slightly medially toward the suprapubic incision on the same side. Once the tape is seen through the incision, the needle is withdrawn while the tape is clamped with a forceps. The bladder catheter is then removed and a cystoscopic examination performed. If the bladder is intact, the same steps are repeated on the other side. Traction on the tape is maintained by placing a plastic umbilical cord clamp on each end of the mesh tape. A layer of sterile gauze is placed underneath a fenestrated plate of stainless steel to avoid skin ischemia. A urethral catheter is inserted to prevent urinary retention from the pressure applied by the plastic olive.

After a short postoperative interval, before discharge, the patient is instructed to take an antibiotic medication for 1 week and a nonsteroidal anti-inflammatory drug (NSAID) whenever required. She is also taught how to void her bowels, care for her urine collection bag, frequently cleanse her vagina with a $10 \%$ povidone iodine solution, and apply sterile vulvar dressings to guard against ascending infection. She returned to the office 3 days later to increase the traction to the tape, and the new traction is maintained using an additional umbilical clamp on each side. If the patient is afraid of experiencing pain from the traction, she is given an intravenous injection of an NSAID 15 minutes before the procedure. The tape, plastic olive, and uretheral catheter are removed on the eighth day after the procedure. During an examination, a medium-sized speculum is inserted into the vagina and the vaginal length is measured and recorded. The patient is encouraged to start sexual intercourse on that day. She presented to the office every 2 weeks for the next 2 months for evaluations. Each spouse is privately asked about dyspareunia and sexual satisfaction at each visit. The husbands are also asked about penetration. A score of 100 is used for satisfaction and penetration. It is a simple scoring chart designed at our institution after the visual analog scale for pelvic pain. After the 2-month follow-up, the couple presented to the clinic only when they had operation-related complaints.

Advantages: TRT vaginoplasty seems to be superior as it does not depend on endoscopy, does not require dissecting the rectovesical space or the vaginal dimple, and is performed relatively quickly. Moreover, the risk of stress incontinence is still present in patients undergoing balloon vaginoplasty because of the posterior traction exerted on the vaginal dimple (62).
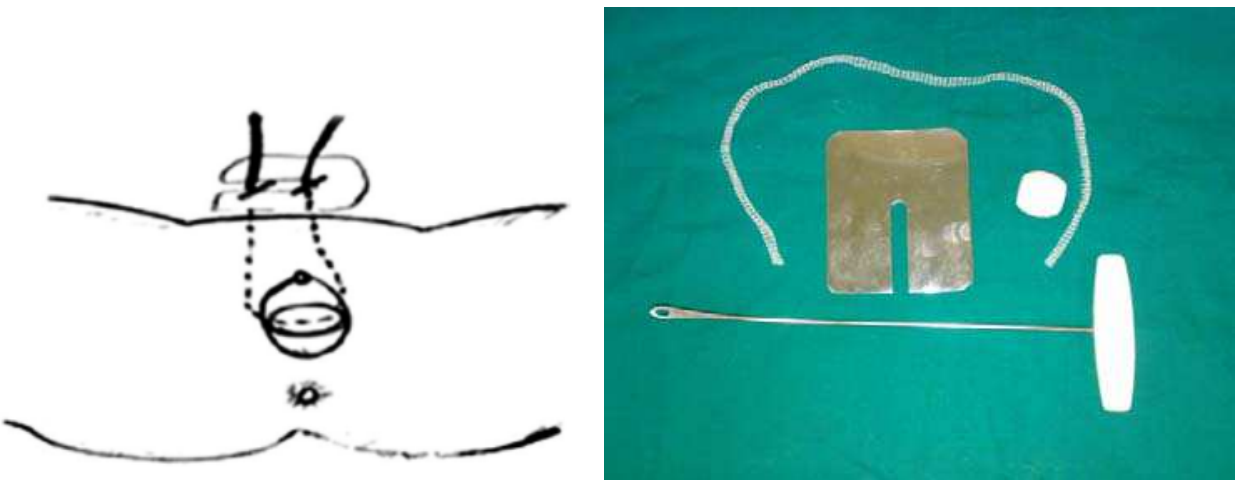

Fig. 18. TRT vaginoplasty 
Disadvantages: a bit sophisticated and these instrumentations are not available in all operating rooms. Moreover, we reported exaggerated patient discomfort and repeated complaints particularly during traction on day 3 . In the following table, I'll summarize the differences between some vaginoplasty techniques.

\begin{tabular}{|c|c|c|c|}
\hline & $\begin{array}{c}\text { Transretropubic (TRT) } \\
\text { vaginoplasty }\end{array}$ & $\begin{array}{c}\text { Laparoscopic } \\
\text { Veccheitti vaginoplasty }\end{array}$ & $\begin{array}{c}\text { Laparoscopic } \\
\text { balloon } \\
\text { vaginoplasty (53) }\end{array}$ \\
\hline $\begin{array}{c}\text { Admission } \\
\text { No need }\end{array}$ & In-patient for 8 days & No need \\
\hline $\begin{array}{c}\text { Slipping of traction } \\
\text { device }\end{array}$ & None & $\begin{array}{c}\text { Mild daily stretching of } \\
\text { the threads }\end{array}$ & Mild once on day 3 \\
\hline Ripping & None & reported & None \\
\hline General anesthesia & Once & possible & None \\
\hline laparoscopic expertise & Usually not needed & Nearly level III & Nearly level II \\
\hline Instrumentation & $\begin{array}{c}\text { Less sophisticated and } \\
\text { reproducible }\end{array}$ & Sophisticated & $\begin{array}{c}\text { Less sophisticated } \\
\text { and reproducible }\end{array}$ \\
\hline Laparoscopy & Usually not needed & needed & needed \\
\hline $\begin{array}{c}\text { Relation to peritoneum } \\
\text { Extraperitoneal }\end{array}$ & $\begin{array}{c}\text { Intraperitoneal or } \\
\text { extraperitoneal }\end{array}$ & Extraperitoneal \\
\hline $\begin{array}{c}\text { Postoperative stress } \\
\text { incontinence }\end{array}$ & $\begin{array}{c}\text { Not possible as it } \\
\text { improves posterior } \\
\text { vesicourethral angle }\end{array}$ & $\begin{array}{c}\text { Possible and reported } \\
(61)\end{array}$ & $\begin{array}{c}\text { Possible but not } \\
\text { reported }\end{array}$ \\
\hline
\end{tabular}

Table 2.

\section{Transretropubic balloon vaginoplasty approach (63)}

The patients are prepared for the operation as for any simple gynecologic surgical procedure. Under spinal anesthesia, bladder evacuation is followed by the insertion of a urethral catheter, through which a rigid guide (or bladder stylet, figure 1) is then passed. This step is taken to mobilize the bladder neck away from the tip of the needle when it passed into the retropubic space. A 5- $\mathrm{mm}$ incision is then made on the midline in the suprapubic area, $2 \mathrm{~cm}$ above the symphysis pubis. A especially designed sharp, curved needle with a wide eye attached to a plastic handle (Fig. 19) is used to perforate the vaginal dimple centrally, just $1 \mathrm{~cm}$ below the bladder neck. The needle is inserted through the vaginal dimple skin without prior incision, directed cephalically upwards and slightly laterally toward the space of Retzius, with simultaneous mobilization of the bladder inwards and laterally on the same side utilizing the bladder stylet. In all cases, the perforation is controlled by perioperative ultrasonographic examination of the space of Retzius. Thereafter, the needle is directed slightly medially toward the suprapubic incision in the midline. Once the fenstrum of the needle is seen through the incision, the distal end of a silicone Foley catheter is fixed to it by a double strengthened Vicryl 2 sutures. Thereafter, the needle is withdrawn downwards and the Vicryl suture is cut leaving the distal end of the Foley catheter outside the vaginal dimple which is immediately filled with 4-6 cc of saline to avoid excessive pain. The bladder catheter is then removed and a cystoscopic 
examination is performed. Upward traction on the catheter is maintained by placing a plastic umbilical cord clamp on its abdominal side. A layer of sterile gauze is placed underneath a fenestrated plate of stainless steel to avoid skin ischemia (Fig. 19). A urethral catheter is inserted to prevent urinary retention from upward traction the inflated balloon. Operative time is recorded for all case. After a short postoperative interval of few hours, before discharge, the patient is instructed to take an antibiotic medication for 1 week and a nonsteroidal anti-inflammatory drug (NSAID) whenever required. She is also taught how to void her bowels, care for her urine collection bag, frequently cleanse her vagina with a $10 \%$ povidone iodine solution, and apply sterile vulvar dressings to guard against ascending infection. She returned to the office 3 days later to increase the upward traction and the size to the balloon by reinflation with extra 3-4 cc of saline and the new traction is maintained using a new umbilical clamp. The suprapubic and uretheral catheters are removed on the 8th day after the procedure.
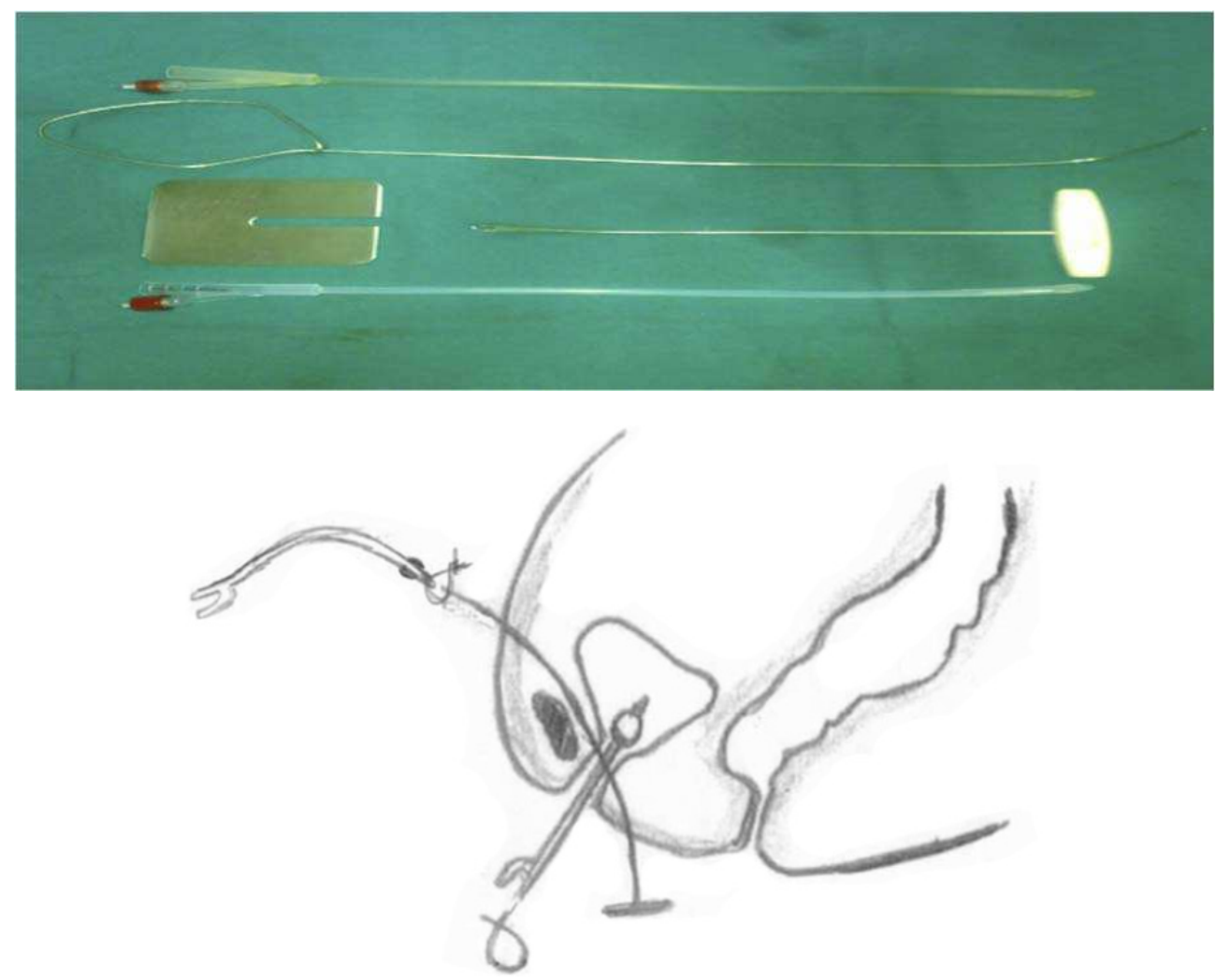

Fig. 19. Transretropubic balloon vaginoplasty: instrumentation and a diagram.

\section{Modified retropubic vaginoplasty(64-66)}

Through a small supra pubic puncture, the catheter inserter is passed from above into the retropubic space just behind the pubic bone and guided to the center of the vaginal dimple. 
Then, a cystoscopic examination is performed to ensure bladder and uretheral integrity. This is followed by gradual controlled distention of the balloon and traction on the catheter stem as described in laparoscopic balloon vaginoplasty.

Drawbacks: this is a relatively unsafe procedure as the inserter is about $5 \mathrm{~mm}$ in caliber and there is no safety issue to protect the urethra from injury during perforation. Non usage of a bladder stylet is another disadvantage as it is used for contralateral displacement of the urethra away from the perforation site. Again, they used perforation from the abdominal site which is considered difficult and unguided if compared with perforation from the vaginal side. Another technical problem of their procedure is the absence of a fenestrum to easily carry threads to the vaginal side.

\section{Which balloon vaginoplasty should I use?}

After this detailed discussion of the published studies on balloon vaginoplasty, I would recommend retropubic balloon vaginoplasty (63) due to the following causes:

Transretropubic balloon vaginoplasty is a simple, fast, safe and available extraperitoneal procedure. It can be easily done by any gynecologist having basic knowledge of the anatomy of the retropubic space. Not only does it save time for the gynecologists, but it also saves a lot of money for the patient and the community as well.

A recent study on laparoscopic balloon vaginoplasty by ElSaman et al reported a case of rectal injury out of three cases (33.3\%). This possibility is remote if the retropubic approach is utilized. Being an extraperitoneal approach makes retropubic balloon vaginoplasty very suitable for cases with extensive intraperitoneal adhesions or with history of intestinal surgery. Moreover, due to its proximity, it seems logic to access the vaginal dimple through it rather than the laparoscopic portals. Retropubic balloon vaginoplasty disturbs neither the urethral support nor the urethrovesical angle. It may even add support to the bladder neck, although for a short period. This technical point is considered as an additional advantage of the retropubic approach over transabdominal conventional or even laparoscopic vaginoplasty. Retropubic balloon vaginoplasty is a good example of minimally-invasive surgery for vaginal aplasia, an anomaly currently corrected with very sophisticated techniques utilizing foreign tissues such as peritoneum, skin, sigmoid, or amnion grafts. Selection of the retropubic space and performing the procedure in the same way as tensionfree tape (TVT) for treating stress incontinence is assuring regarding safety and is confirmed by absence of complications in our pilot study. It seems that this transretropubic balloon vaginoplasty is superior to transretropubic vaginoplasty using a tape and an olive in terms of shorter mean operative time ( $8.5 \mathrm{vs}$. $26.5 \mathrm{~min})$ due to single perforation of the space of Retzius, elimination of the exaggerated intolerable pain on traction on the tape that required analgesics in all cases of the previous study, and utilization of the silicone balloon with easier traction due to elastic recoil character and changeable balloon size. Clearly, this procedure is much cheaper than transretropubic vaginoplasty.

A modified retropubic vaginoplasty has been recently published by ElSaman et al. The authors used an inserter carrying threads at its distal end and passed from the suprapubic side towards the vaginal dimple. This instrument is short and straight unlike the long curved needle used in this study. Moreover, their procedure is blind and completely unsafe as this instrument has a wide caliber with a high possibility of urethral injury. Out of three cases, they reported one case of urethral damage (33.3\%) that required catheterization for 8 days. Another technical problem of their procedure is the absence of a fenestrum to easily carry threads to the vaginal side. 


\section{References}

[1] Evans PN, Poland NL, Boving RL: Vaginal malformations. Am J Obstet Gynecol 1981;141:910-920.

[2] Poland ML, Evans TN. Psychologic aspects of vaginal agenesis. J Reprod Med. 1985;30(4):340-4.

[3] Morgan EM, Quint EH. Assessment of sexual functioning, mental health, and life goals in women with vaginal agenesis. Arch Sex Behav. 2006;35(5):607-18.

[4] Prapas Y., Papanicolaou A., Prapas N., Goutzioulis M., Papanicolaou N. Term pregnancy after vaginal transplantation in a case of vaginal agenesis with a functional uterus. Acta Europaea fertilitatis 1993;24 (2), 77-78.

[5] Paniel B, Haddad B. Utero-vaginal aplasia and pregnancy. Journal de Gynecologie Obstetrique et Biologie de la Reproduction1994; 23 (5), 626-628.

[6] Moura M D, Navarro P, Nogueira A. Pregnancy and term delivery after neovaginoplasty in a patient with vaginal agenesis. International Journal of Gynecology and Obstetrics 2000; 71 (3),215-21.

[7] Brannstrom $M$, Wranning CA. Uterus transplantation: How far away from human trials? Acta Obstet Gynecol Scand. 2008;87(11):1097-1100.

[8] Gosden RG. Ovary and Uterus Transplantation. Reproduction. 2008 Aug 26, in press.

[9] Wranning CA, Akhi SN, Kurlberg G, Brannstrom M. Uterus transplantation in the rat: Model development, surgical learning and morphological evaluation of healing. Acta Obstet Gynecol Scand. 2008;87(11):1239-1247.

[10] Dahm-Kähler P, Wranning C, Lundmark C, Enskog A, Mölne J, Marcickiewicz J et al.. Transplantation of the uterus in sheep: methodology and early reperfusion events. J Obstet Gynaecol Res. 2008;34(5):784-93.

[11] Dittrich R, Beckmann MW, Mueller A, Binder H, Hoffmann I, Maltaris T. Uterus Cryopreservation: Maintenance of Uterine Contractility by the Use of Different Cryoprotocols. Reprod Domest Anim. 2008 Oct 13, in press.

[12] Ulrich U, Schrickel J, Dorn C, Richter O, Lewalter T, Lu“deritz B, Rhiem K. Mayer-von Rokitansky-Ku"ster-Hauser syndrome in association with a hitherto undescribed variant of the Holt-Oram syndrome with an aorto-pulmonary window. Hum Reprod 2004;19:1201-3.

[13] Croak AJ, Gebhart JB, Klingele CJ, Lee RA, Rayburn WF. Therapeutic strategies for vaginal Mullerian agenesis. J Reprod Med 2003;48:395-401.

[14] Wierrani F, Grunberger W. Vaginoplasty using deepithelialized vulvar transposition flaps: the Grunberger method. J Am Coll Surg 2003;196:159-162.

[15] Noguchi S, Nakatsuka M, Sugiyama Y, Chekir C, Kamada Y, Hiramatsu Y. Use of artificial dermis and recombinant basic fibroblast growth factor for creating a neovagina in a patient with Mayer-Rokitansky-Kuster-Hauser syndrome. Hum Reprod 2004;19:1629-1632.

[16] Motoyama S, Laoag-Fernandez JB, Mochizuki S, Yamabe S, Maruo T. Vaginoplasty with Interceed absorbable adhesion barrier for complete squamous epithelialization in vaginal agenesis. Am J Obstet Gynecol 2003;188:1260-1264.

[17] Jackson ND, Rosenblatt PL. Use of Interceed Absorbable Adhesion Barrier for vaginoplasty. Obstet Gynecol 1994;84:1048-1050. 
[18] Dietrich JE, Hertweck SP, Traynor MP, Reinstine JH. Laparoscopically assisted creation of a neovagina using the Louisville modification. Fertil Steril 2007;88:1431-1434.

[19] Cai B, Zhang JR, Xi XW, Yan Q, Wan XP. Laparoscopically assisted sigmoid colon vaginoplasty in women with Mayer-Rokitansky-Kuster-Hauser syndrome: feasibility and short-term results. Bjog 2007;114:1486-1492.

[20] Bailez MM. Laparoscopy in uterovaginal anomalies. Semin Pediatr Surg 2007;16:278-287.

[21] Michala L, Cutner A, Creighton SM. Surgical approaches to treating vaginal agenesis. Bjog 2007;114:1455-1459.

[22] Rock JA, Schlaff WD. The obstetric consequences of uterovaginal anomalies. Fertil Steril 1985;43:681-692.

[23] Mc IA. The treatment of congenital absence and obliterative conditions of the vagina. $\mathrm{Br}$ J Plast Surg 1950;2:254-267.

[24] Buttram VC, Jr., Gibbons WE. Mullerian anomalies: a proposed classification. (An analysis of 144 cases). Fertil Steril 1979;32:40-46.

[25] Andryjowicz E, Qizilbash AH, DePetrillo AD, O'Connell GJ, Taylor MH. Adenocarcinoma in a cecal neovagina--complication of irradiation: report of a case and review of literature. Gynecol Oncol 1985;21:235-239.

[26] Rotmensch J, Rosenshein N, Dillon M, Murphy A, Woodruff JD. Carcinoma arising in the neovagina: case report and review of the literature. Obstet Gynecol 1983;61:534-536.

[27] Williams EA. Congenital Absence of the Vagina: a Simple Operation for Its Relief. J Obstet Gynaecol Br Commonw 1964;71:511-512.

[28] Fedele L, Bianchi S, Frontino G, Fontana E, Restelli E, Bruni V. The laparoscopic Vecchietti's modified technique in Rokitansky syndrome: anatomic, functional, and sexual long-term results. Am J Obstet Gynecol 2008;198:377 e371-376.

[29] Fedele L, Busacca M, Candiani M, Vignali M. Laparoscopic creation of a neovagina in Mayer-Rokitansky-Kuster-Hauser syndrome by modification of Vecchietti's operation. Am J Obstet Gynecol 1994;171:268-269.

[30] Mizia K, Bennett MJ, Dudley J, Morrisey J. Mu“llerian dysgenesis: a review of recent outcomes at Royal Hospital forWomen. Aust NZJ Obstet Gynaecol 2006;46:29-31.

[31] Laffargue F, Giacalone PL, Boulot P, Vigouroux B, Hedon B, Benos P. A laparoscopic procedure for the treatment of vaginal aplasia. Br J Obstet Gynaecol 1995;102:565-7.

[32] Ismail IS, Cutner AS, Creighton SM. Laparoscopic vaginoplasty: alternative techniques in vaginal reconstruction. BJOG 2006;113:340-3.

[33] Lotan G, Mashiach R, Halevy A. Total endoscopic vaginal reconstruction in a case of Mayer-Rokitansky-Kuster-Hauser syndrome. J Laparoendosc Adv Surg Tech A 2005;15:435-8.

[34] Charvat M, Horejsi J, Teslik L. Laparoscopic neovaginoplasty-a modification of the Vecchietti operation. Ceska Gynekol 2001;66:247-51.

[35] Cooper MJ, Fleming S, Murray J. Laparoscopic assisted Vecchietti procedure for the creation of a neovagina. J Obstet Gynaecol Res 1996;22:385-8.

[36] Fedele L, Bianchi S, Berlanda N, Fontana E, Bulfoni A, Borruto F. Laparoscopic creation of a neovagina with the laparoscopic Vecchietti operation: comparison of two instrument sets. Fertil Steril 2006;86:429-32. 
[37] Fedele L, Bianchi S, Dorta M, Zanconato G, Raffaelli R. Laparoscopic creation of a neovagina in women with pelvic kidney. J Am Assoc Gynecol Laparosc 1999;6:327-9.

[38] Giacalone PL, Laffargue F, Faure JM, Deschamps F. Ultrasound-assisted laparoscopic creation of a neovagina by modification of Vecchietti's operation. Obstet Gynecol 1999;93:446-8.

[39] Giacalone PL, Laffargue F, Bousquet F, Faure JM, Deschamps F. Creation of a neovagina using ultrasonography-assisted laparoscopy (modified Vecchietti technique). J Gynecol Obstet Biol Reprod 1998;27:514-6.

[40] Bianchi M, Sola V, Ricci P, Pomes C. Late postoperative urinary stress incontinence after a laparoscopic-assisted Vecchietti procedure for neovagina creation in a patient with Rokitansky syndrome: successful treatment with the TVT-O technique. J Minim Invasive Gynecol 2007;14(1):116-8.

[41] Jansen FW, Kolkman W, Bakkum EA, de Kroon CD, Trimbos-Kemper TC, Trimbos JB. Complications of laparoscopy: an inquiry about closed- versus open-entry technique. Am J Obstet Gynecol 2004;190(3):634-8.

[42] Ohashi S, Ikuma K, Koyasu Y, Tei K, Kanno H, Akashi A, Haque SM. Laparoscopic reconstruction of vagina using sigmoid autograft. Surg Endosc 1996;10:1019-21.

[43] Crouch NS, Creighton SM. Sigmoid colpoplasty for vaginal agenesis. Fertil Steril 2004;81:1721.

[44] Soong YK. Laparoscopically assisted neovaginoplasty. In: Tulandi T, ed. Atlas of laparoscopic and hysteroscopic techniques for gynecologists. London: Saunders, 1999. Chapter 24.

[45] Adamian LV, Zurabiani ZR, Kiselev SI, Khashukoeva AZ. Laparoscopy in surgical treatment of vaginal aplasia: laparoscopy-assisted colpopoiesis and perineal hysterectomy with colpopoiesis. Int J Fertil Menopausal Stud 1996;41:40-5.

[46] Adamian LV, Zurabiani ZR, Kiselev SI, Khashukoeva AZ. Laparoscopy in surgical treatment of vaginal aplasia: laparoscopy-assisted colpopoiesis and perineal hysterectomy with colpopoiesis. Int J Fertil Menopausal Stud 1996;41:40-5.

[47] Schober JM. Cancer of the neovagina. J Pediatr Urol 2007;3:167-70.

[48] Liao L, Doyle J, Crouch NS, Creighton SM. Dilation as treatment for vaginal agenesis and hypoplasia: a pilot exploration of benefits and barriers as perceived by patients. J Obstet Gynaecol 2006;26:144-8.

[49] Ismail-Pratt IS, Bikoo M, Liao LM, Conway GS, Creighton SM. Normalization of the vagina by dilator treatment alone in Complete Androgen Insensitivity Syndrome and Mayer-Rokitansky-Kuster-Hauser Syndrome. Hum Reprod 2007;22:2020-4.

[50] Laufer MR. Congenital absence of the vagina: in search of the perfect solution. When, and by what technique, should a vagina be created? Curr Opin Obstet Gynecol 2002;14:441-4.

[51] Abramov Y,Webb A, Miller J, Alshahrour A, Botros S, Goldberg R, et al. Biomechanical characterization of vaginal versus abdominal surgical wound healing in the rabbit. Am J Obstet Gynecol 2003;194:1472-7.

[52] Abramov Y, Gandhi S, Botros S, Goldberg R, ShermanW, Rurak M, et al. Do alterations in vaginal dimensions after reconstructive pelvic surgeries affect the risk for dyspareunia? Am J Obstet Gynecol 2005;192:1573-7. 
[53] Atef M.M. Darwish. A simplified novel laparoscopic formation of neovagina in cases of Mayer-von Rokitansky-Kuster-Hauser syndrome Fertil Steril. 2007;88(5):1427-30.

[54] El Saman AM, Fathalla MM, Nasr AM, Youssef MA. Laparoscopically assisted balloon vaginoplasty for management of vaginal aplasia. Int J Gynecol Obstet 2007;98:134-7.

[55] El Saman AM, Zakheraha MS, Nasra AM, Fathalla MM. Distension versus traction in laparoscopically assisted balloon vaginoplasty for management of vaginal aplasia. Int J Gynecol Obstet 2007;98:134-7.

[56] El Saman AM, Fathalla MM, Zakherah MS, Shaaban OM, Nasr A. Modified balloon vaginoplasty: the fastest way to create a natural: minor changes in technique eliminate the need for customized instruments. Am J Obstet Gynecol. 2009; 201(5):546 e1-5.

[57] El Saman AM, Ismael AM, Zakherah MS, Nasr A, Tawfik RM, Bedaiwy MA.Enhancement balloon vaginoplasty for treatment of blind vagina due to androgen insensitivity syndrome. Fertil Steril. 2011 Feb;95(2):779-82

[58] Mirilas P, Colborn GL, McClusky DA 3rd, Skandalakis LJ, Skandalakis PN, Skandalakis JE. The history of anatomy and surgery of the preperitoneal space. Arch Surg 2005;140:90-4.

[59] Darwish AM. Fine needle vaginoplasty: a simplified novel approach for correction of vaginal aplasia. Fertil Steril. 2010 Jun;94(1):309-12.

[60] Darwish AM. Transretropubic traction vaginoplasty for correction of vaginal aplasia. Int J Gynaecol Obstet. 2009 Dec;107(3):262-5

[61] Bent AE. Sling and bulking agent placement procedures. Rev Urol 2004;6 (Suppl 5):S26-46.

[62] Bianchi M, Sola V, Ricci P, Pomes C. Late postoperative urinary stress incontinence after a laparoscopic-assisted Vecchietti procedure for neovagina creation in a patient with Rokitansky syndrome: successful treatment with the TVT-O technique. J Minim Invasive Gynecol 2007;14(1):116-8.

[63] Darwish AM, Mohammad AM. A new era for treating vaginal aplasia using transretropubic balloon vaginoplasty approach. Fertil Steril. 2011 Mar 1;95(3):1104-8.

[64] El Saman AM. Retropubic balloon vaginoplasty for management of Mayer-RokitanskyKuster-Hauser syndrome. Fertil Steril 2009.

[65] El Saman AM. Combined retropubic balloon vaginoplasty and laparoscopic canalization: a novel blend of techniques provides a minimally invasive treatment for cervicovaginal aplasia. Am J Obstet Gynecol 2009;201:333 e331-335

[66] El Saman AM. Retropubic balloon vaginoplasty for management of Mayer-RokitanskyKüster-Hauser syndrome. Fertil Steril. 2010 Apr;93(6):2016-9.) 


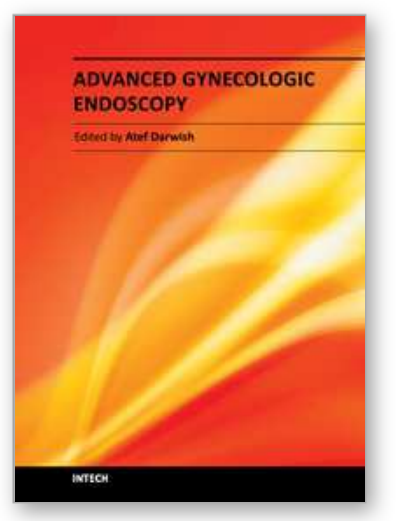

\author{
Advanced Gynecologic Endoscopy \\ Edited by Dr. Atef Darwish
}

ISBN 978-953-307-348-4

Hard cover, 332 pages

Publisher InTech

Published online 23, August, 2011

Published in print edition August, 2011

The main purpose of this book is to address some important issues related to gynecologic laparoscopy. Since the early breakthroughs by its pioneers, laparoscopic gynecologic surgery has gained popularity due to developments in illumination and instrumentation that led to the emergence of laparoscopy in the late 1980's as a credible diagnostic as well as therapeutic intervention. This book is unique in that it will review common, useful information about certain laparoscopic procedures, including technique and instruments, and then discuss common difficulties faced during each operation. We also discuss the uncommon and occasionally even anecdotal cases and the safest ways to deal with them. We are honored to have had a group of world experts in laparoscopic gynecologic surgery valuably contribute to our book.

\title{
How to reference
}

In order to correctly reference this scholarly work, feel free to copy and paste the following:

Atef M.M. Darwish (2011). Balloon Vaginoplasty: A Revolutionary Approach for Treating Vaginal Aplasia, Advanced Gynecologic Endoscopy, Dr. Atef Darwish (Ed.), ISBN: 978-953-307-348-4, InTech, Available from: http://www.intechopen.com/books/advanced-gynecologic-endoscopy/balloon-vaginoplasty-a-revolutionaryapproach-for-treating-vaginal-aplasia

\section{INTECH}

open science | open minds

\section{InTech Europe}

University Campus STeP Ri

Slavka Krautzeka 83/A

51000 Rijeka, Croatia

Phone: +385 (51) 770447

Fax: +385 (51) 686166

www.intechopen.com

\section{InTech China}

Unit 405, Office Block, Hotel Equatorial Shanghai

No.65, Yan An Road (West), Shanghai, 200040, China

中国上海市延安西路65号上海国际贵都大饭店办公楼405单元

Phone: +86-21-62489820

Fax: +86-21-62489821 
(C) 2011 The Author(s). Licensee IntechOpen. This chapter is distributed under the terms of the Creative Commons Attribution-NonCommercialShareAlike-3.0 License, which permits use, distribution and reproduction for non-commercial purposes, provided the original is properly cited and derivative works building on this content are distributed under the same license. 